\title{
An experimental method for recording the behaviour of human isolated colonic segments
}

\author{
ANNE BUCKNELL ${ }^{1}$ AND C. CLARK ${ }^{2}$ \\ From the Department of Surgery, King's College Hospital Medical School, Denmark Hill, London
}

EDITORIAL COMMENT A technique for the study of muscle activity in isolated segments of human colon is described. This permits correlation of propulsive movements and pressure behaviour with muscle activity of a spontaneous character as well as allowing the use of pharmacological agents and electrical stimulation methods.

The patterns of motility demonstrated by the normal and diseased human colon in situ have been studied extensively by intraluminal pressure recording and ciné-radiography (Chaudhary and Truelove, 1961; Ritchie, Ardran, and Truelove, 1962; Painter, Truelove, Ardran, and Tuckey, 1965; Deller and Wangel, 1965). However, the underlying nervous and muscular factors responsible for coordinated colonic movements are still poorly understood.

An experimental system has been designed for studies of the behaviour of complete segments of human colon in vitro. This method permits a more complete analysis of the mechanisms involved in motility than is possible in vivo.

Segments of colon removed at operation were maintained viable by perfusion of both the vascular bed and lumen of the specimen with Krebs' solution. ${ }^{3}$ The preparation was supported horizontally in an organ bath filled with the same solution. One end of the segment was free to move, to allow recording of muscle activity. Intraluminal pressures and outflow from the lumen were also recorded.

The experimental system therefore comprised an organ bath, vascular and intraluminal perfusion systems, and electronic transducers for the recording of data.

\section{THE ORGAN BATH}

A perspex organ bath, $35 \mathrm{~cm}$. long, $13 \mathrm{~cm}$. wide by $11 \mathrm{~cm}$. deep, and open on the upper surface was used. At one end a tapered connector of uniform internal diameter $1.5 \mathrm{~cm}$. Present Address:

${ }^{1}$ Department of Pharmacolcgy, Harvard Medical School, 25 Shattuck Street, Boston, Massachusetts, U.S.A.

Department of Mechanical Engineering, Massachusetts Institute of Technolog $y$, Cambridg z, Massachusetts, U.S.A.

${ }^{8}$ Composition of Krebs' solution in g./litre: $\mathrm{NaCl}, 6.9 ; \mathrm{KCl}, 0.35$; $\mathrm{CaCl}_{2} \cdot 6 \mathrm{H}_{2} \mathrm{O}, 0.55 ; \mathrm{KH}_{2} \mathrm{PO}_{4} \cdot 7 \mathrm{H}_{2} \mathrm{O}, 0.29$; d-glucose, $1.0 ; \mathrm{NaHCO}_{3}$, $2 \cdot 1$. was mounted in the wall of the bath for attachment of the proximal end of the gut (fixed cannula in Fig. 1). The distal end was connected to a free-sliding cannula, $8 \mathrm{~cm}$. long and internal diameter $2.5 \mathrm{~cm}$. (Fig. 1). The sliding cannula was constructed from a $50 \mathrm{ml}$. polythene test tube. A glass tube, $1 \mathrm{~cm}$. long and $0.5 \mathrm{~cm}$. internal diameter, was inserted into the rounded end of the cannula. A light flexible coil of tubing joined the cannula to an outflow connector in the wall of the organ bath.

The coil consisted of a $30 \mathrm{~cm}$. length of knitted Teflon arterial substitute of $0.8 \mathrm{~cm}$. internal diameter, which was covered with thin-walled latex tubing. This compound tube produced a watertight and extremely flexible coil. The sliding cannula was supported on a bearing surface in a perspex bridge, which was polished to reduce frictional resistance to movement of the cannula. The position of the bridge could be varied to accommodate different lengths of colon by sliding it along two parallel bars.

The bath held approximately 5 litres of Krebs' solution which was changed by a steady inflow of heated solution from a reservoir. This fluid was bubbled continuously with $95 \% \mathrm{O}_{2}, 5 \% \mathrm{CO}_{2}$. The organ bath was mounted in a thermostatically controlled water bath to maintain the Krebs' solution at a temperature of 35 to $36^{\circ} \mathrm{C}$.

\section{VASCULAR PERFUSION}

Physiological fluid was perfused through the mesenteric vessels to maintain viability of the colon. Oxygenated Krebs' solution at $36^{\circ} \mathrm{C}$. was supplied to the cannulated arteries by a roller pump which delivered $21 \mathrm{ml}$. per minute. Venous effluent was not recorded and flowed to waste at a site remote from the organ bath.

\section{INTRALUMINAL PERFUSION}

The lumen of the segment was filled with Krebs' solution which was supplied from a constant head reservoir (Mariotte bottle) at the proximal end of the gut (Fig. 1). The solution passed through heat exchange coils in the 
water bath and through the fixed cannula into the lumen. Just upstream of the cannula a vertical glass tube $(60 \mathrm{~cm}$. long) was connected through a Y-piece to the supply tubing, to act as a gas bubble trap (Fig. 2). Pressure in the gut lumen could be varied by adjusting the level of the Mariotte bottle.

\section{MEASUREMENT OF OUTFLOW FROM THE LUMEN}

The Krebs' solution expelled from the distal end of the segment passed through the sliding cannula and flexible coil to a volume flow recorder (Fig. 2). To obtain a measure of propulsive activity of the gut in an aboral direction, two conditions were maintained:

(a) The end of the outflow tubing leading from the lumen was supported in the same horizontal plane as the atmospheric pressure level in the Mariotte bottle (Fig. 1). This condition was met for all levels of the reservoir; therefore flow occurred only as a result of colonic activity.

(b) The length and diameter of the inflow and outflow tubing were selected to give equal flow resistances. In general, tubes with unequal resistances to flow on either side of the colon segment may result in maximum fluid movement in the direction of least resistance. This may therefore lead to false conclusions regarding propulsive activity.

The outflow was collected in a cylinder of uniform bore and the hydrostatic pressure at the base of the liquid column was recorded (Sanborn pressure transducer, model no. 268B). The cylinder was emptied periodically using a relay controlled valve. Pressure changes recorded were then directly proportional to liquid volume changes, and both instantaneous and mean outflow rates could be determined.
METHOD OF RECORDING INTRALUMINAL PRESSURES

Intraluminal pressures were recorded at two points using rigid polythene catheters of $1 \mathrm{~mm}$. uniform bore. Openended flexible nylon tubing was used for the terminal $4 \mathrm{~cm}$. of the catheters, to prevent damage to the mucosa. The catheters were passed into the lumen through a T-connector at the upstream end of the segment (Fig. 2). Each catheter was connected to a variable inductance pressure transducer (Sanborn model no. 268B); the tubes and transducers were filled with saline.

To permit pressure recording with atmospheric pressure as a reference level, each transducer zero level was positioned in the same horizontal plane as the catheter tip.

\section{METHOD OF RECORDING MUSCLE ACTIVITY}

Movements of the gut in a longitudinal direction were recorded from the sliding cannula (Fig. 2). Silk threads, attached to side arms on the cannula, passed through a pulley system to a reduction lever attached to the core of an isotonic linear displacement transducer (Sanborn Linearsyn model no. 585 DT 5). A total external working load of 20 to $25 \mathrm{~g}$. was applied to the segment, through the lever.

The resistance to longitudinal movement of the colon offered by the cannula, flexible coil, pulleys, and unloaded lever system was less than $5 \%$ of the total tension applied to the segment. Therefore, the recordings made from this system were considered to be under conditions of isotonic loading.

The transducers used for recording outflow, pressures, and linear displacement were connested to a multichannel pen recorder (Sanborn, model no. 350). All data were therefore recorded simultaneously.

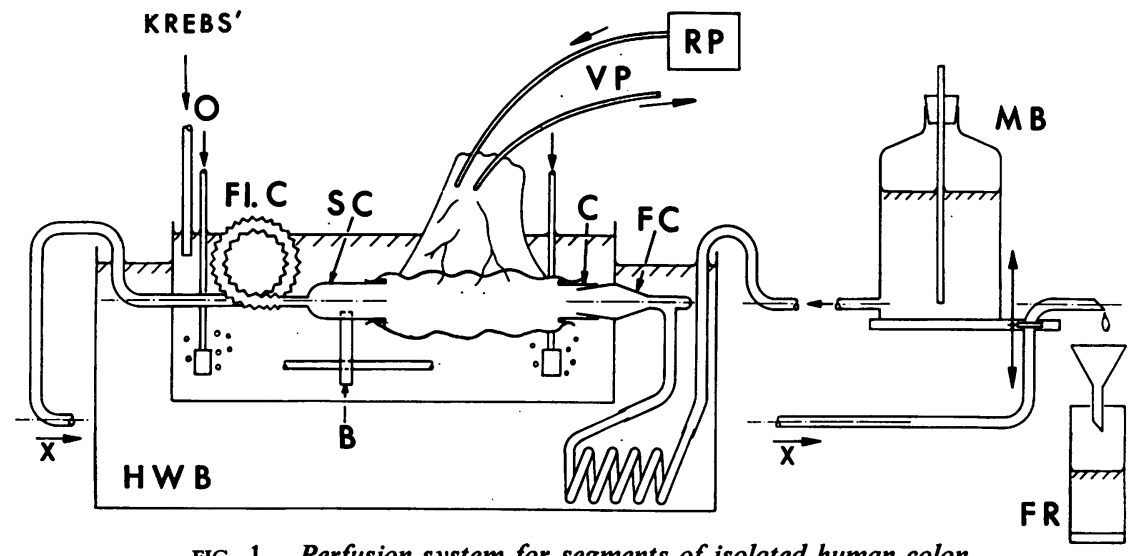

FIG. 1. Perfusion system for segments of isolated human colon.

$M B \quad$ Mariotte bottle reservoir of Krebs' solution

FC fixed cannula at proximal end of segment

$C$ connector

SC sliding cannula at distal end of segment

$B \quad$ bridge support for sliding cannula

FlC flexible coil

$X X \quad$ outflow tube interrupted for clarity

$F R \quad$ luminal outflow recorder
Krebs' continuous inflow of solution to organ bath

$\mathrm{O}$ continuous supply of gas $\left(95 \% \mathrm{O}_{2}, 5 \% \mathrm{CO}_{2}\right)$

$H W B$ heated water bath to maintain organ bath at $36^{\circ} \mathrm{C}$.

$R P \quad$ roller pump for vascular perfusion

$V P$ arterial and venous catheters for vascular perfusion 


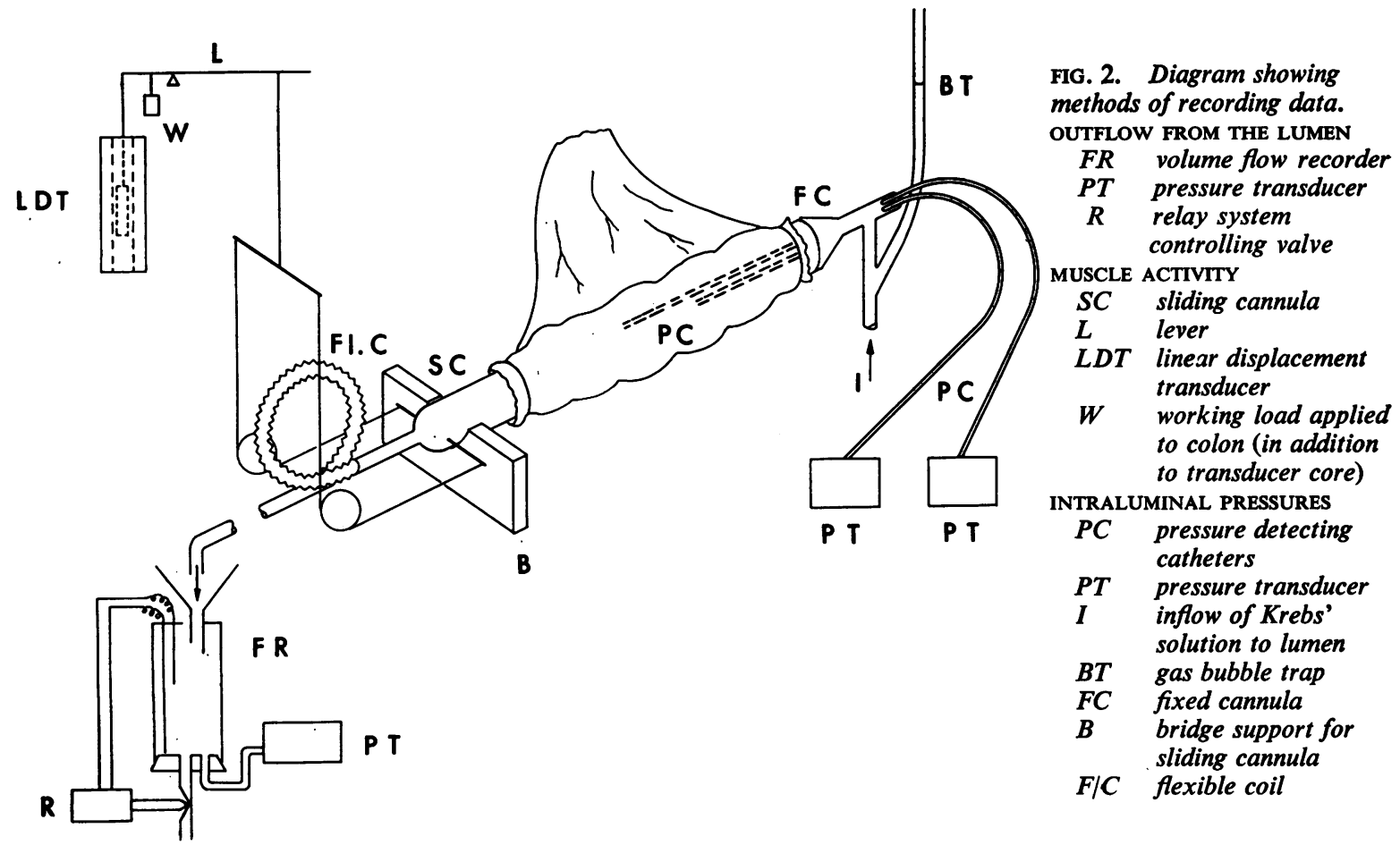

PREPARATION OF THE COLON SEGMENT

Segments of colon 15 to $20 \mathrm{~cm}$. long, with the mesocolon intact, were obtained from operation specimens, immediately following resection. The segments were removed from regions which were macroscopically least affected by disease, and the lumen thoroughly washed with Krebs' solution.

The cut ends of the main artery and vein supplying the segment were identified in the mesocolon, and cannulated with rigid polythene tubes. To provide adequate perfusion it was found necessary to cannulate more than one artery in some specimens. Krebs' solution was injected through the arterial cannula to remove blood and permit identification of cut vessels, which were ligated. The arterial cannula was then connected to the vascular perfusion system.

A polythene connector was tied to the proximal end of the segment and the preparation immersed in the organ bath and gently squeezed to remove air from the lumen. The connector was pushed firmly onto the tapered fixed cannula to secure the proximal end of the segment, and the distal end was then tied to the sliding cannula. The supporting bridge was positioned approximately at the midpoint of the sliding cannula, to allow free movement in both directions. Air was removed from the pressure recording catheters by flushing them through with saline.

Free flow through the lumen of the segment was checked by transiently raising the Mariotte bottle, and an external load was applied to the colon through the reduction lever. An equilibration period of 30 minutes was allowed, with the Mariotte bottle at zero level.

\section{DISCUSSION}

Specimens of colon studied using this system exhibited spontaneous rhythmic muscle activity for a period of six to eight hours. Associated with this activity was the appearance of intraluminal pressure waves, the amplitude and frequency of which were similar to those due to segmental activity of the colon in situ (Connell, 1961; Ritchie et al., 1962; Connell, 1965).

A typical recording is presented in Figure 3. The rhythmic muscle activity and associated pressure waves are clearly shown. Differences between the two pressure recordings are probably due to some form of segmental behaviour. Outflow from the lumen is indicated by upward deflections in the record; two short phases of flow may be seen.

This experimental method therefore permits correlation of both propulsion of luminal contents and pressure behaviour, with muscle activity. Studies in vivo have been limited to observations of the movement of luminal contents and pressure behaviour, only.

The gut specimens were mounted horizontally in this system to eliminate the non-uniformities due to hydrostatic pressure, which would occur if the segments were mounted vertically. The relationship between spontaneous muscle activity and resting intraluminal pressure can be investigated by varying 
the height of the Mariotte bottle reservoir supplying the lumen.

Muscle activity is recorded in a longitudinal direction only. To some extent this represents a measure of the combined actions of both longitudinal and circular muscle; since, in general, circular muscle activity produces a component of movement in the longitudinal direction. More detailed information could be obtained from independent recordings of circular and longitudinal muscle movements, as described by Jacoby, Bass, and Bennett (1963).

The recorded outflow from the distal end of the lumen is an indication of propulsion of luminal contents in the aboral direction. Movement of the contents in an oral direction was seen to occur, but was not recorded.

Considerable oedema was found to be present in

FIG. 3. Typical recording from an isolated segment of human colon showing spontaneous activity. In descending order the records are:

longitudinal movement of the colon outflow from the lumen (upward deflections represent flow)

intraluminal pressures at two points, $3 \mathrm{~cm}$. apart (calibration is in cm. water) the submucosa, muscle layers, and mesocolon of these specimens following perfusion for a period of four to six hours. This was probably due both to water absorption from the vascular and luminal perfusate and inadequate lymphatic drainage. Oedema may be reduced if a plasma substitute or haemoglobin suspension is added to the perfusing solutions. The latter would also increase the oxygen-carrying capacity of the solution and may extend the period of viability.

This experimental system is suitable for studies on the motility of several regions of the intestinal tract of man and other mammals. The system is also suitable for ciné-radiographic studies on the movement of luminal contents during muscle activity. An analysis of the mechanisms involved in colonic motility may be performed using pharmacological agents and electrical stimulation techniques.

\section{SUMMARY}

An experimental system is described which permits analysis of the motility of complete segments of human colon in vitro. The segments are maintained viable by intraluminal and intravascular perfusions

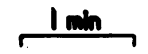

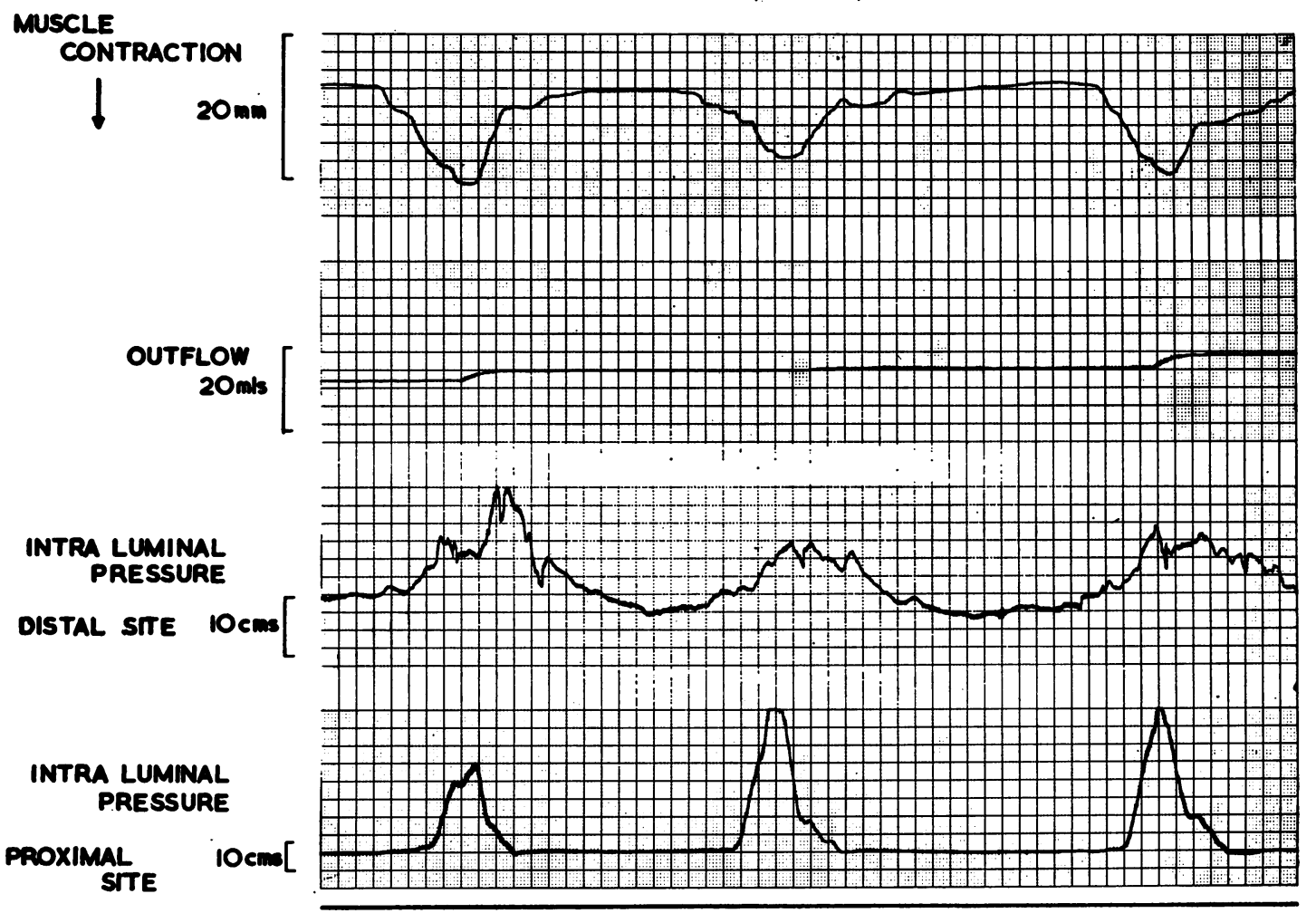


of Krebs' solution and exhibit spontaneous rhythmic muscle activity for a period of six to eight hours. Methods of recording intraluminal pressure, outflow from the lumen, and muscle activity are presented.

We are very grateful to Mr. C. T. Howe for his criticism of this manuscript. This work was presented to the Surgical Research Society of Great Britain and Ireland in July 1966, and formed part of a thesis for the degree of Ph.D. of London University (A.B.).

We gratefully acknowledge support from the M.R.C. (A.B.) and King's College Hospital (C.C.).

\section{REFERENCES}

Chaudhary, N. A., and Truelove, S. C. (1961). Human colonic motility: a comparative study of normal subjects, patients with ulcerative colitis, and patients with the irritable colon syndrome. I. Resting patterns of motility. Gastroenterology, 40, 1-17.

Connell, A. M. (1961). The motility of the pelvic colon. 1. Motility in normals and in patients with asymptomatic duodenal ulcer. Gut, 2, 175-186.

- (1965). Significance of the pressure waves of the sigmoid colon. Amer. J. dig. Dis., 10, 455-462.

Deller, D. J., and Wangel, A. G. (1965). Intestinal motility in man. I. A study combining the use of intraluminal pressure recording and cineradicgraphy. Gastroenterology, 48, 45-57.

Jacoby, H. I., Bass, P., and Bennett, D. R. (1963). In vivo extraluminal contractile force transducer for gastrointestinal muscle. J. appl. Physiol., 18, 658-665.

Painter, N. S., Truelove, S. C., Ardran, G. M., and Tuckey, M. (1965). Effect of morphine, prostigmine, pethidine, and probanthine on the human colon in diverticulosis studied by intraluminal pressure recording and cineradicgraphy. Gut, 6, 57-63.

Ritchie, J. A., Ardran, G. M., and Truelove, S. C. (1962). Motor activity of the sigmoid colon of humans: a combined study by intraluminal pressure recording and cineradiography. Gastroenterology, 43, 642-668. 